\title{
排出管径を变化したときのホッパからの粉体の重力による流出 ${ }^{\dagger}$
}

\author{
山城光雄
}

\author{
足利工業大学 経営工学科 $^{\dagger \dagger}$
}

\section{久野 洋}

\section{慶應義塾大学理工学部 応用化学科 ${ }^{\dagger \dagger}$}

\section{緒言}

排出管を付設したホッパからの粉体の重力による流出 に関する研究の中で, 著者ら ${ }^{11}$ は以前に排出管の内径を 一定として長さを変化させたときのオリフィス直下の管 内圧力上流出速度を求好実験を行い, 次式が成立する ことを示した。

$$
W=C \rho_{B}^{1 / 2}\left(P_{2}-P_{1}\right)^{1 / 2}\left(D-k d^{1 / 2}\right)^{2}
$$

ここに, $W\left[\mathrm{~g} \cdot \mathrm{s}^{-1}\right]$ は粉体の流出速度, $P_{1}$ 抢よび $P_{2}[\mathrm{~Pa}]$ はホッパ出口直下抢よび直上の压力, $D[\mathrm{~cm}]$ はオリフィ 径, $d[\mathrm{~cm}]$ は粉体の粒径, $\rho_{B}\left[\mathrm{~g} \cdot \mathrm{cm}^{-3}\right]$ は粉体層の見 かけ密度, $C$ と $k$ は定数である.

本報告では, 排出管の内径を系統的飞変化させて上述 と同様な実験を行い，前報のデータを含めて Eq. (1)の成 立について，管径の影響を検討した。

\section{1. 実験}

試料扮よび装置は前報”之同様である。試料の性質を Tables 1 と 2 亿示す.ホッパの排出管の長さを 7 段階 $(0,25,50,75,100,125$, 打よび $150 \mathrm{~cm})$, 内径を 4 段階 $(1.3,1.0,0.8$, および $0.6 \mathrm{~cm})$ 亿変えて実験を行った。

\section{2. 結果}

\section{$2 \cdot 1$ 単一粉体}

オリフィス直下の管内圧力と流出速度との関係の一例 をFig. 1 亿示す.

Eq. (1) が排出管を付けないときも成立すると仮定すれ ば, 次式を得る.

$$
\begin{aligned}
P_{1}-P_{0}=-\left(P_{2}-P_{0}\right) & \left(W / W_{0}\right)^{2} \\
& +\left(P_{2}-P_{0}\right)
\end{aligned}
$$

ここに, $W_{0}$ は排出管を付けない場合の粉体の流出速度 である.排出管の内径を変えたすべての場合に対して, $P_{1}-P_{0}$ と $\left(W / W_{0}\right)^{2}$ との関係を求めた結果, 直線関係が 得られ, Eq. (2)が成立した.

Eq. (1)を変形すると，

$$
\begin{aligned}
& \text { † 1988年 } 8 \text { 月 } 22 \text { 日受理 } \\
& \text { †† } \mathbf{T} 326 \text { 足利市大前町 } 268 \\
& \text { †† } \mathbf{T} 223 \text { 横浜市港北区日吉 } 3-14-1
\end{aligned}
$$

$$
\begin{array}{r}
{\left[W /\left\{\rho_{B}^{1 / 2}\left(P_{2}-P_{1}\right)^{1 / 2}\right\}\right]^{1 / 2}} \\
=C^{1 / 2} D-k C^{1 / 2} d^{1 / 2}
\end{array}
$$

となる。 $W$ と $\rho_{B}{ }^{1 / 2}\left(P_{2}-P_{1}\right)^{1 / 2}$ との関係を, 単一粉体の 各粒径について求め, 得られた直線関係の勾配より $W /$ $\left\{\rho_{B}^{1 / 2}\left(P_{2}-P_{1}\right)^{1 / 2}\right\}$ を求めた. 乙の值を $G$ 上すると, Eq. (3) は次式のようになる.

$$
G^{1 / 2}=C^{1 / 2} D-k C^{1 / 2} d^{1 / 2}
$$

試料にガラスビーズとポリスチレンを用いて各粒径でと の $G^{1 / 2}$ を Dに対してプロットしたと乙ろ，Fig. 2 亿示す ように両者の間にほぼ直線的な関係が得られた。直線の 勾配之縦軸の切片より計算して得られた $C$ および $k$ の値 をTable 1 亿示す. $C$ と $k$ の值を Eq. (1) 飞代入して得ら れた流出速度の計算值は，Fig. 1 亿実線で示すように測 定值よよく一致した。

\section{$2 \cdot 2$ 混合粉体}

同種之異種の混合粉体について同様の実験を行い，得 られた $C$ とをTable 2 に示した。 これより，単一粉体 の場合と同様に同種㧍よび異種の混合粉体にも Eq.(1)が 適用できることが再確認された。

\section{結論}

排出管の内径および長さを変化させて粉体の流出実験 を行ったと乙ろ, 単一粉体と同種抢よび異種の混合粉体 に対してEq.(1) が成立し, 前報の結果がより広範な条 件下で成立することを確認した。

[ 謝 辞 ] 本研究をまとめるにあたり，で指導いただい た慶應義塾大学理工学部応用化学科・仙名保教授に感謝の意を 表します。

\section{Nomenclature}

$$
\begin{aligned}
& C=\text { constant } \\
& D=\text { efflux tube diameter } \\
& {\left[\mathrm{g}^{1 / 2} \cdot \mathrm{Pa}^{-1 / 2} \cdot \mathrm{cm}^{-1 / 2} \cdot \mathrm{s}^{-1}\right]} \\
& \text { [cm] } \\
& d \text { = particle diameter } \\
& d_{a v}=\text { average particle diameter } \\
& k=\text { constant } \\
& \text { [mm or } \mathrm{cm}] \\
& \text { [mm or } \mathrm{cm}] \\
& {\left[\mathrm{cm}^{1 / 2}\right]}
\end{aligned}
$$


Table 1 Properties of powders

\begin{tabular}{|c|c|c|c|c|c|}
\hline Sample & $\begin{array}{l}\text { Particle diameter } \\
d[\mathrm{~mm}]\end{array}$ & $\begin{array}{c}\text { True density } \\
\rho\left[\mathrm{g} \cdot \mathrm{cm}^{-3}\right]\end{array}$ & $\begin{array}{c}\text { Apparent density } \\
\rho_{B}\left[\mathrm{~g} \cdot \mathrm{cm}^{-3}\right]\end{array}$ & $\begin{array}{c}\text { Constants } \\
C \\
{\left[\mathrm{~g}^{1 / 2} \cdot \mathrm{Pa}^{-1 / 2} \cdot \mathrm{cm}^{-1 / 2} \cdot \mathrm{s}^{-1}\right]}\end{array}$ & $\begin{array}{c}k \\
{\left[\mathrm{~cm}^{1 / 2}\right]}\end{array}$ \\
\hline \multirow[t]{3}{*}{ Glass } & 0.180 & 2.424 & 1.428 & 2.50 & 0.9 \\
\hline & 0.505 & 2.501 & 1.434 & 2.29 & 0.7 \\
\hline & 1.015 & 2.486 & 1.477 & 2.22 & 0.7 \\
\hline \multirow[t]{2}{*}{ Polystyrene } & 0.180 & 1.056 & 0.647 & 2.42 & 0.9 \\
\hline & 0.505 & 1.071 & 0.613 & 2.32 & 0.8 \\
\hline
\end{tabular}

Table 2 Properties of mixed powders

\begin{tabular}{|c|c|c|c|c|c|}
\hline Sample & $\begin{array}{l}\text { Volume fraction } \\
\text { of larger paricles } \\
\qquad \phi[-]\end{array}$ & $\begin{array}{l}\text { Apparent density } \\
\qquad \rho_{B}\left[\mathrm{~g} \cdot \mathrm{cm}^{-3}\right]\end{array}$ & $\begin{array}{l}\text { Geometric average of } \\
\text { particle diameter } \\
d_{a v}[\mathrm{~mm}]\end{array}$ & $\begin{array}{c}\text { Constants } \\
C \\
{\left[\mathrm{~g}^{1 / 2} \cdot \mathrm{Pa}^{-1 / 2} \cdot \mathrm{cm}^{-1 / 2} \cdot \mathrm{s}^{-1}\right]}\end{array}$ & $\begin{array}{c}k \\
{\left[\mathrm{~cm}^{1 / 2}\right]}\end{array}$ \\
\hline \multirow{3}{*}{$\begin{array}{l}\text { Glass }(d: 1.435 \mathrm{~mm} \\
\text { and } 0.180 \mathrm{~mm})\end{array}$} & 0.75 & 1.712 & 0.847 & 2.24 & 0.9 \\
\hline & 0.50 & 1.715 & 0.505 & 2.53 & 0.9 \\
\hline & 0.24 & 1.552 & 0.297 & 2.36 & 0.7 \\
\hline Polystyrene & 0.74 & 0.751 & 0.832 & 2.07 & 0.7 \\
\hline$(d: 1.435 \mathrm{~mm}$ and & 0.50 & 0.749 & 0.505 & 2.62 & 1.0 \\
\hline $0.180 \mathrm{~mm})$ & 0.25 & 0.760 & 0.301 & 2.45 & 1.0 \\
\hline Glass $(d: 1.435 \mathrm{~mm})$ & 0.74 & 1.475 & 0.840 & 2.19 & 1.1 \\
\hline and Polystyrene & 0.48 & 1.211 & 0.491 & 2.49 & 1.1 \\
\hline$(d: 0.180 \mathrm{~mm})$ & 0.24 & 0.938 & 0.297 & 2.51 & 1.0 \\
\hline Glass $(d: 0.180 \mathrm{~mm})$ & 0.74 & 1.012 & 0.837 & 2.18 & 0.6 \\
\hline and Polystyrene & 0.48 & 1.191 & 0.493 & 2.08 & 0.4 \\
\hline$(d: 1.435 \mathrm{~mm})$ & 0.25 & 1.363 & 0.301 & 2.28 & 0.6 \\
\hline
\end{tabular}

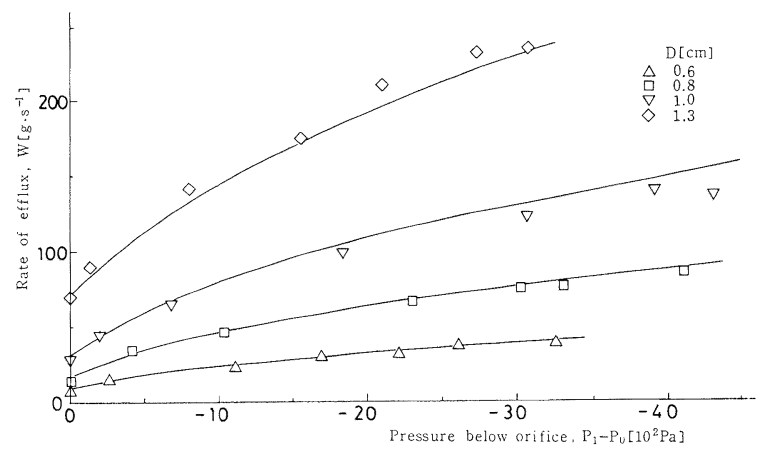

Fig. 1 Relation between rate of efflux and pressure below orifice. Glass. $d: 0.180 \mathrm{~mm}$.

$l \quad=$ tube length

$P_{0}=$ atomospheric pressure

$P_{1}=$ pressure below orifice

[cm]

$P_{2}=$ pressure above orifice

$[\mathrm{Pa}]$

$W=$ rate of efflux with an efflux tube $\left[\mathrm{g} \cdot \mathrm{s}^{-1}\right]$

$W_{0}=$ rate of efflux without an efflux tube $\left[\mathrm{g} \cdot \mathrm{s}^{-1}\right]$

$\rho \quad=$ true density of powder

$\left[\mathrm{g} \cdot \mathrm{cm}^{-3}\right]$

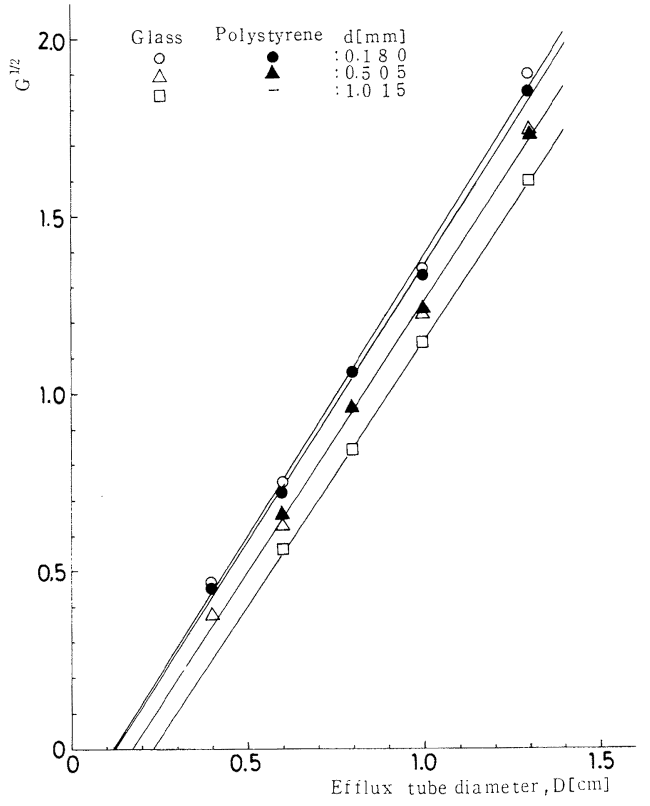

Fig. 2 Relation between $G^{1 / 2}$ ard efflux tube diameter 
$\rho_{B}=$ apparent density of powder
$\phi \quad=$ volume fraction of larger particles $\left[\mathrm{g} \cdot \mathrm{cm}^{-3}\right] \quad$ Literature cited

$[-]$
1) Yamashiro, M. and H. Kuno: Kagaku Kogaku Ronbunshu, 14, 46 (1988)

\section{Effect of Efflux Tube Size on Gravity Flow of Powders from a Hopper}

\section{Mitsuo Yamashiro}

Dept. of Industrial and Systems Eng. Ashikaga Inst. of Tech., Ashikaga 326

\section{Hiroshi Kuno}

Dept. of Applied Chemistry, Keio Univ., Yokohama 223

Key Words : Hopper, Powder, Gravity Flow, Efflux Tube, Efflux Rate

Additional experiments on gravity flow of powders from a hopper were carried out by varying the diameter of the efflux tube, $\boldsymbol{D}$, to reconfirm the following semi - theoretical equation :

$$
\boldsymbol{W}=\boldsymbol{C} \rho_{B}^{1 / 2}\left(\boldsymbol{P}_{2}-\boldsymbol{P}_{1}\right)^{1 / 2}\left(\boldsymbol{D}-\boldsymbol{k} \boldsymbol{d}^{1 / 2}\right)^{2}
$$

where $\boldsymbol{W}$ is the efflux rate of powder; $\rho_{B}$ the apparent density of the powder in the hopper ; $\boldsymbol{P}_{2}$ and $\boldsymbol{P}_{1}$ the pressure above and below the orifice; $\boldsymbol{d}$ the particle diameter ; and $\boldsymbol{C}$ and $\boldsymbol{k}$ are constants.

\section{凍結乾燥における凍結粒子の濡れ壁塔を用いた連続製造法 ${ }^{\dagger}$ \\ 横田俊幸・大戸行雄 \\ 山形大学工学部 化学工学科 $^{\dagger \dagger}$}

凍結乾燥法による金属酸化物の微粉体の製造は，活性 の高い粉体が得られることから、ファインセラミックス 用の原料粉体の製造法として大いに注目を浴びている. この方法は，1968年 Schnettler ら ${ }^{5)}$ によって提案されて いらい, 多くの研究がなされその有用性が示されている ${ }^{1,2,3)}$ が，いまだ工業的規模での応用はなされず，実験室 的利用にとどまっている，その理由として，プロセスの 連続化が難しい, 装置が高価である，また乾燥過程に時 間がかかる，などが挙げられている。

本報告では, 凍結乾燥プロセスの中の凍結操作を取り

† 1988年 9 月28日受理; 化学工学協会第20回秋季大会（姫路, 1987年10月）にて 部発表

计 $\mathbf{9} 992$ 米沢市城南 4-3-16
上げ，微小液滴の凍結を効率的に行い，工業的規模での 利用も可能な新しい凍結粒子製造装置を開発したので報 告する.

てれまでの凍結粒子の製造法は, Schnettler らが提案 した方法と基本的には変わらず, 凍結バス中に液柱ある いは液滴を噴霧し，乙れを凍らすむのである。乙の方法 の問題点として，回分方式であるため処理量に制限があ る, 原料溶液の注入量が増えると凍結バスの温度が変化 する, 注入した液滴同士の衝突, 合一や凍結粒子の凝集 が起きることがある，凍結粒子の捕集に手間がかかる， などがある，連続式の凍結粒子製造法としはSauer ら ${ }^{4)}$ が提案した方法がある。乙れは, 低温窒素ガスにて冷や した有機化合物の冷媒の中に, 原料の金属塩水溶液を泠 